\title{
Estimation of thyroid equivalent doses during evacuation based on body surface contamination levels in the nuclear accident of FDNPS in 2011
}

\author{
Takashi Ohba ${ }^{1,2}$, Arifumi Hasegawa ${ }^{3}$, Yoshitaka Kohayakawa $^{4}$, Hisayoshi Kondo ${ }^{4}$, Gen Suzuki ${ }^{5,}$ \\ ${ }^{1}$ Department of Radiation Health Management, Fukushima Medical University, 1 Hikarigaoka Fukushima, Japan \\ ${ }^{2}$ Barcelona Institute for Global Health (ISGlobal), 88 Doctor Aiguader Barcelona, Spain \\ ${ }_{3}^{3}$ Department of Radiation Disaster Medicine, Fukushima Medical University, 1 Hikarigaoka Fukushima, Japan \\ ${ }^{4}$ National Hospital Organization Disaster Medical Center, 3256 Midorimachi Tachikawa, Japan \\ ${ }^{5}$ International University of Health and Welfare Clinic, 2600-1 Kitakanemaru Ohtawara, Japan
}

\begin{abstract}
To reduce uncertainty in thyroid dose estimation, residents' radiation protection behavior should be reflected in the estimation. Screening data of body surface contamination provide information on exposure levels during evacuation. Our purpose is to estimate thyroid equivalent doses based on body surface contamination levels using a new methodology. We obtained a record of 7,539 residents/evacuees. Geiger-Mueller survey meter measurement value in $\mathrm{cpm}$ was translated into $\mathrm{Bq} / \mathrm{cm}^{2}$ according to the nuclides densities obtained by measuring clothing from two persons by germanium $\gamma$-spectrometer. The measurement value of body surface contamination on head was adjusted by a natural removal rate of 15 hours and radionuclides' physical half-life. Thyroid equivalent dose of 1-year-old children by inhalation was estimated by two-dimensional Monte Carlo simulation. The proportions of evacuees/residents with measurement value in cpm of Namie and Minamisoma groups were higher than those of other groups during both periods ( $\mathrm{p}<0.01$, Kruskal-Wallis). During 12-14 March period, 50 and 95 percentiles of thyroid equivalent doses by inhalation were estimated as 2.7 and $86.0 \mathrm{mSv}$, respectively, for Namie group, and 4.2 and $17.2 \mathrm{mSv}$, respectively, for Minamisoma group, 0.1 and $1.0 \mathrm{mSv}$, respectively, for Tomioka/Okuma/Futaba/Naraha group, and 0.2 and $2.1 \mathrm{mSv}$, respectively, for the other group. During 1517 March period, 50 and 95 percentiles of thyroid equivalent doses by inhalation were 0.8 and $15.7 \mathrm{mSv}$, respectively, for Namie group, and 1.6 and $8.4 \mathrm{mSv}$, respectively, for Minamisoma group, 0.2 and $13.2 \mathrm{mSv}$, respectively, for Tomioka/Okuma/Futaba/Naraha group, and 1.2 and $12.7 \mathrm{mSv}$, respectively, for the other group. It was indicated that inhalation dose was generally higher in Namie and Minamisoma groups during 12-14 March than those during 15-17 March might reflect different self-protective behavior to radioactive plumes from other groups.
\end{abstract}

\section{Introduction}

The risk of childhood thyroid cancer is a major concern after the nuclear accident at the Fukushima Daiichi Nuclear Power Station (FDNPS) in March 2011 [1]. Because of paucity in direct thyroid measurements after the accident [2,3], thyroid equivalent doses were estimated by an atmospheric transfer, dispersion and deposition model (ATDM) using a source term by Terada in UNSCEAR 2013 Report [4]. However, the UNSCEAR's estimates of settlement-averaged thyroid doses were two to five times higher than the corresponding values based on direct measurements. This discrepancy might be, at least in part, due to the difficulty in estimating temporal and spatial nuclides concentrations in the air by ATDM and individual selfprotective behavior during evacuation.
Most residents living in the Fukushima Prefecture were screened for their body surface contaminations by Geiger-Mueller (GM) survey meter [5,6]. Screening survey was started from 12 March and conducted about 43,000 residents until 17 March [5]. These residents began evacuating within a radius of $20 \mathrm{~km}$ from the FDNPS at 18:25 (JST) on 12 March [4]. Since only a small fraction of radioactive plume blew inland, the time and direction of plumes that blew inland and residents' behavior at the occasion were important factors for exposure. A radioactive plume released at evening on 12 March directed to north-northwest direction [7], many evacuees who evacuated to this direction might have been exposed. In addition, a radioactive plume released from the FDNPS on 15 and 16 March blew inland from south-southwest direction in the morning and changing the direction clock wisely into north-west [7], many

Corresponding author: gensuzki@iuhw.ac.jp 
residents might have been exposed to plume but at rather remote places from the FDNPS.

To reduce uncertainty in thyroid dose estimation, residents' radiation protection behavior should be considered in the estimation. The levels of body surface contamination might reflect the exposure levels during evacuation. In the present study, we introduced a new methodology for estimating thyroid doses based on the levels of body surface contamination.

\section{Methods}

\subsection{Principals of analysis}

\subsubsection{Calculation of radionuclide density $\left(\mathrm{Bq} / \mathrm{cm}^{2}\right)$ from screening survey using GM survey meter}

Body surface contamination density $S_{i}(T)\left(\mathrm{Bq} / \mathrm{cm}^{2}\right)$ of radionuclide- $i$ was calculated by the following formula in (1), where $N$ and $N_{b}$ represent GM measurements (count per minute; cpm) of body surface and background, respectively, $\varepsilon_{e, i}$ and $\varepsilon_{s, i}$ are instrument efficiency and emission efficiency of $\beta$-ray, $W\left(\mathrm{~cm}^{2}\right)$ is detector area, and $E R_{i}$ is emission rate of $\beta$ - ray [8].

$$
S_{i}(T)=\frac{\left(N-N_{b}\right)}{\varepsilon_{e, i} \cdot W \cdot \varepsilon_{s, i} \cdot E R_{i}}
$$

\subsubsection{Conversion of $\beta$-ray into radionuclide densities}

GM survey meter measures almost all $\beta$ emissions from radionuclides. In order to estimate thyroid equivalent dose, one has to know the composition of $\beta$-ray from radionuclides on cloths and body surface. Radionuclides' composition on clothing of two persons was measured by a whole body counter (WBC) equipped with germanium (Ge) $\gamma$-spectrometer (AccuScan by CANBERRA Industries Inc.).

We utilized this composition for body surface contamination by a plume on 12 March. As to radionuclides composition on body surface during 15-17 March, we adopted air dust sampling data by Japan Atomic Energy Agency (JAEA) in Tokai Village [9]. Major radionuclides contributing screening survey, i.e., ${ }^{131} \mathrm{I},{ }^{132} \mathrm{I},{ }^{133} \mathrm{I},{ }^{135} \mathrm{I},{ }^{132} \mathrm{Te},{ }^{134} \mathrm{Cs}$, and ${ }^{137} \mathrm{Cs}$, were determined in Becquerel (Bq). As relative radionuclides' composition on body surface was known, the $\beta$-ray proportion from each radionuclide was calculated using equipment efficiency in each $\beta$-ray energy and major $\beta$ ray emission rate in each radionuclide using equation (1).

\subsubsection{Natural removal rate}

The natural removal rate of sub-micron particles from human skin was reported to be $14.7 \mathrm{~h}$ [10]. In the analyses, we used $15 \mathrm{~h}$ for particulate radionuclides as well as for elemental radioiodine. The average of multiple measurements on head and neck, at most 6 , was considered as the representative value of individual, as there were no statistically significant differences in contamination levels among head, hand and clothing in the same individual [6].

Body surface contamination density $S_{i}$ (at plume) $\left(\mathrm{Bq} / \mathrm{cm}^{2}\right)$ of radionuclide- $i$ at the time of exposure of the plume was calculated by a following formula in (2), where $T_{s c r}(\mathrm{~h})$ is the time from exposure of the plume to measurement of body surface contamination, $H L_{i}(\mathrm{~h})$ is a half-life of each radionuclide, and $15(\mathrm{~h})$ is a half-life of the natural remove.

$$
S_{i}(\text { at plume })=S_{i}(T) \cdot\left(0.5^{\frac{T_{s c r}}{H L_{i}}} \times 0.5^{\frac{T_{s c r}}{15.0}}\right)
$$

We assumed that the first exposure ending time to plume was set up at 19:00 on 12 March. Natural removal rate was calculated from the first exposure ending time to screening survey time at 12:00 on 13 March, or at 12:00 on 14 March. The second exposure ending time to plume was set up at 9:00 on 16 March because of the plume to south-southwest direction began blowing in the morning on 15 March, and changing the direction clock wisely into north-west, and finally to east direction in the morning on 16 March [7]. The natural removal rate was calculated from the second exposure ending to screening survey time at $12: 00$ on 16 March, or at 12:00 on 17 March. As to evacuees/residents who were measured on 15 March, we did not apply natural removal rate.

\subsubsection{Thyroid dose estimation model by inhalation based on body surface contamination level}

On the assumption that radionuclide- $i$ deposits on body surface with a dry deposition velocity of $v_{i}(\mathrm{~cm} / \mathrm{s})$, then cumulative body surface contamination density $S_{i}$ (at plume) $\left(\mathrm{Bq} / \mathrm{cm}^{2}\right)$ during evacuation from time 0 to time $T$ (hour), as shown in Figure 1., would be

$$
S_{i}(\text { at plume })=3.6 \times 10^{-3} \int_{0}^{T} v_{i} A_{i}(t) d t
$$

, where $A_{i}(t)$ represents radionuclide- $i$ concentration in the air at time $t\left(\mathrm{~Bq} / \mathrm{m}^{3}\right)$.

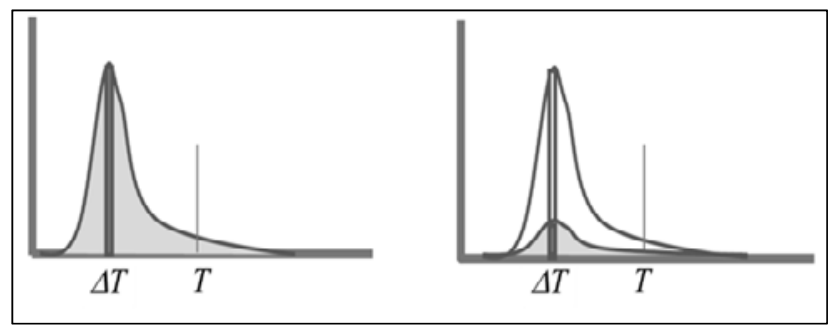

Fig. 1. The contents of a cumulative body surface contamination density Si (at plume) $\left(\mathrm{Bq} / \mathrm{cm}^{2}\right)$ during evacuation from time 0 to time $\mathrm{T}$ (hour).

On the other hand, inhalation thyroid equivalent dose on (4), $E D_{\text {i-thy }}$ (at plume), (Sv) during times 0 to $T$ hour is expressed as

$$
E D_{i-\text { thy }}(\text { at plume })=B \cdot T \cdot f_{i} \frac{\int_{0}^{T} A_{i}(t) d t}{T}
$$




$$
=\frac{B \cdot f_{i} \cdot S_{i}(\text { at plume })}{3.6 \times 10^{-3} \cdot v_{i}}
$$

, where $B\left(\mathrm{~m}^{3} / \mathrm{h}\right)$ is age-specific ventilation parameter at light exercise (1-year-old), and $f i$ is an age-specific thyroid dose coefficient (1-year-old) of ICRP Publication 71 [11]. As $S_{i}$ (at plume) can be calculated using measurement value $S_{i}(T)$ in equation (1) and equation (2), $E D_{i-t h y}$ (at plume) can be estimated if $v_{i}$ is given.

\subsubsection{Physicochemical forms of radionuclide}

Radioiodine ( ${ }^{131} \mathrm{I}$ ) was assumed to be composed of $20 \%$ elementary iodine, $30 \%$ methyl-iodine, and 50\% particulate iodine, which was referred from Katata et al. [7]. On the other hand, radioiodine $\left({ }^{132} \mathrm{I},{ }^{133} \mathrm{I}\right)$ were assumed to be composed of $50 \%$ elementary iodine, and $50 \%$ particulate iodine [9]. ${ }^{132} \mathrm{Te}$, and ${ }^{137} \mathrm{Cs}$ were assumed to be composed of $100 \%$ particulate form.

By comparing ${ }^{132} \mathrm{Te} /{ }^{131} \mathrm{I}$ ratio on cloths in our data and that of air dust samplings on 12 March at $20 \mathrm{~km}$-zone from the FDNPS [12], relative deposition velocity of ${ }^{132} \mathrm{Te}$ was estimated to be 1.2-times faster than that of ${ }^{131} \mathrm{I}$.

\subsubsection{Two-dimensional Monte Carlo simulation}

Two-dimensional Monte Carlo (2D-MC) simulation was conducted using a Monte Carlo sampling method by Crystal Ball (release 11.1.2.3.500, Kozo Keikaku Engineering Inc. Tokyo, Japan) on the assumption that $v_{i}$ followed a uniform distribution ranging from 0.1 to 0.5 $\mathrm{cm} / \mathrm{s}$, and body surface contamination levels followed district-specific lognormal-, exponential- or Weiblldistribution, of which parameters were automatically selected by Crystal Ball software based on AndersonDarling (A-D) statistics. The upper and lower bounds of the uniform distribution were adopted from reports on the FDNPS accident, the Windscale accident, and the SL-1 accident [13-17]. 2D-MC simulation was performed 200-times for uncertain $v_{i}$ part combined with 2000-times for variable part, i.e., cpm distribution. Deposition velocity of ${ }^{132} \mathrm{Te}$ was modified by 1.2 -times based on the difference of ${ }^{132} \mathrm{Te} /{ }^{131} \mathrm{I}$ ratios between dust sampling data on 12 March and WBC data of two persons' clothing.

\subsection{Analysis of data}

\subsubsection{GM survey meter screening}

Body surface contamination was measured in cpm at 5 $\mathrm{cm}$ apart from body surface with a GM survey meter equipped with $\$ 50 \mathrm{~mm}$-probe (TGS-133, TGS-136, and TGS-146; Hitachi-Aloka Medical, Ltd. and so on.) wrapped with a plastic cling film. Multiple measurements were done in the same individual from head to feet and results were written in an individual formatted sheet. The upper limit of measurement was $100,000 \mathrm{cpm}$. A detailed method of screening survey was reported elsewhere $[5,6]$.
From the local government of Fukushima Prefecture, we obtained 7,291 records, as of May 2016. There were 6 completely blank records and 7,285 records were included in the present analysis. In addition, 254 residents/evacuees were screened by GM survey meter in Fukushima Medical University (FMU) hospital, and we pooled those 7,285 and 254 records. Thus, 7,539 evacuees/residents were the subject in the present analysis. Each record contained personal information including residence town, age, gender, date of screening, screening place, and measurements data in cpm on a body map.

This study was approved by the Ethics Committee of International University of Health and Welfare (Approval number: 13-B-79) as well as by the Ethics Committee of FMU (Approval number: No. 2136).

\subsubsection{Data cleaning and Statistical analysis}

There were 4 categories of records, such as "BG (background)", "Measurement value in cpm (including over 13,000 cpm)", "No measurement value recorded (no description about the measurement value of body surface contamination)", and "Specific symbols ((hyphen), o (circle), / (slash), $\checkmark$, OK, None, " $<10,000$ cpm", Normal, and so on)". We interviewed several screening teams on these symbols, but as of the end of August 2016, we could not determine whether these symbols represented "Value over BG but less than screening level". Thus, in the present study, we categorized data into "BG", and "Measurement value in cpm", "No measurement value recorded (over background but less than screening level, i.e., 13,000 cpm)", and "Specific Symbols". In the analyses, measured values were subtracted by $60 \mathrm{cpm}$ in order to estimate thyroid equivalent dose at 1 -year-old by inhalation. Finally, the value was log-transformed in the analyses.

According to evacuation directions, the evacuees/residents were classified into 4 district-groups; Tomioka/Okuma/Futaba/Naraha group, Namie group, Minamisoma group, and the other group. The other group consisted of residents living in Hirono Town, Tamura City, Kawauchi Village, Katsurao Village, Iitate Village, other 21 municipalities in Fukushima Prefecture, and outside Fukushima area. Since radioactive plumes flew over inland on 12 March and on 15 and 16 March [7], the distribution of surface contamination of residents was classified by 2 different periods: during 12-14 March period, and during 15-17 March period.

IBM SPSS Statistics for Windows ver. 23.0.0.2 software package (IBM Corp., Armonk, NY, USA) was used for statistical analyses. $x^{2}$-Test was used to compare proportions of over $13,000 \mathrm{cpm}$ in 4 district-groups (Tomioka/Okuma/Futaba/Naraha group, Namie group, Minamisoma group, and the other group) using post hoc $z$-Test contributed Bonferroni collection, Kruskal-Wallis to compare the measurement value (cpm) in 4 districtgroups, and post hoc analyses were performed automatically multiple comparison analysis in SPSS. 
The $p$-values of $<0.05$ were considered statistically significant.

\section{Results}

\subsection{The summary of contamination level in residents}

The demographic feature of screened subjects were $41.9 \pm 23.5$ (mean \pm SD) years old (ranged 0-100, excluding 353 missing data), and $49.1 \%$ males (excluding 721 missing data). Table 1 showed subject numbers in each contamination category. The proportion of "BG", "Measurement value in cpm", "No measurement value recorded", and "Specific symbols" were $2.4 \%, 27.7 \%, 33.7 \%$, and $36.2 \%$, respectively. Among evacuees/residents who had data about body surface contamination, only $0.4 \%$ of evacuees/residents showed contamination levels over $13,000 \mathrm{cpm}$. The proportion of over $13,000 \mathrm{cpm}$ in Namie group was higher than any other group during both periods $\left(p<0.001, x^{2}\right.$-Test $)$.

Table 1. The proportion of categorical contamination levels.

\begin{tabular}{|c|c|c|c|c|c|}
\hline $\begin{array}{l}\text { Subjects' living } \\
\text { area on } 11 \text { th } \\
\text { March } 2011\end{array}$ & BG & $\begin{array}{l}\text { Measurement } \\
\text { value in cpm } \\
\text { [Over } 13,000 \\
\text { cpm] }\end{array}$ & $\begin{array}{l}\text { No measurement } \\
\text { value recorded }\end{array}$ & $\begin{array}{l}\text { Specific } \\
\text { symbols }\end{array}$ & Total \\
\hline $\begin{array}{l}\text { Tomioka/Okuma/ } \\
\text { Futaba/Naraha }\end{array}$ & 81 & $893[10]$ & 937 & 705 & \multirow[t]{2}{*}{2,626} \\
\hline (\%) & (3.1) & $(34.0)(0.4)$ & (35.7) & (26.8) & \\
\hline Namie & 31 & $328 \quad[15]$ & 272 & 321 & \multirow{2}{*}{967} \\
\hline$(\%)$ & (3.2) & (33.9) (1.6) & (28.1) & $(33.2)$ & \\
\hline Minamisoma & 20 & $589 \quad[0]$ & 781 & 688 & \multirow{2}{*}{2,078} \\
\hline$(\%)$ & (1.0) & $(28.3)(0.0)$ & (37.6) & (33.1) & \\
\hline The other* & 46 & $250 \quad[2]$ & 552 & 1,018 & \multirow{2}{*}{1,868} \\
\hline (\%) & (2.5) & $(13.4)(0.1)$ & (29.5) & $(54.5)$ & \\
\hline Total & 178 & $2,060 \quad[27]$ & 2,542 & 2,732 & \multirow{2}{*}{7,539} \\
\hline$(\%)$ & (2.4) & $(27.3)(0.4)$ & (33.7) & $(36.2)$ & \\
\hline
\end{tabular}

* The address of the other group included Hirono Town, Tamura City, Kawauchi Village, Katsurao Village, Iitate Village, the other 21 municipalities in Fukushima Prefecture, and outside Fukushima area.

\subsection{Body surface contamination level in residents after modifying natural removal rate}

The box-and-whisker plots of body surface contamination levels are shown in Figure 2.

During 12-14 March periods, the levels of measurement values in cpm were almost same between Namie and Minamisoma groups, but statistically higher than those of Tomioka/Okuma/Futaba/Naraha group and the other group $(p<0.01$, Kruskal-Wallis). (Figure 2). During 15-17 March period, the contamination levels of Tomioka/Okuma/Futaba/Naraha group was statistically the lowest in all groups $(p<0.001$, Kruskal-Wallis). It was noted that the contamination levels in the other group, that included Kawamata, Iitate, Katurao villages located north-west direction from FDNPS, increased and became comparable to the levels in Namie and Minamisoma groups (Figure 2).

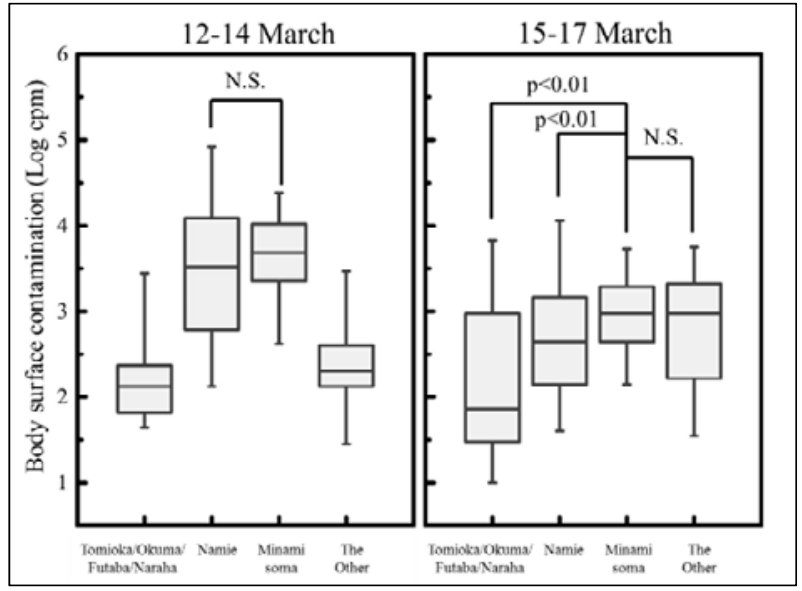

Fig. 2. The box-and-whisker plots of body surface contamination after natural remove collection. N.S. is no significant.

\subsection{Radionuclides' ratio in the air and clothing}

Table 2 depicted the temporal pattern of radionuclides' ratios in the air based on WBC and air dust samplings. It was demonstrated that ${ }^{132} \mathrm{Te} /{ }^{131} \mathrm{I}$ ratio by air dust sampling within $20 \mathrm{~km}$ radius from the FDNPS on 12 March was almost the same as those by WBC measurements of cloths of two persons exposed on the same day after modifying physical decay. On 12 March, ${ }^{132} \mathrm{Te} /{ }^{131} \mathrm{I}$ ratio was 1.50 by source term, 1.93 by air dust samplings $(\mathrm{N}=3)$ within $20 \mathrm{~km}$ radius from the FDNPS, and 1.79 by the estimated air radioactive concentration using conversion factor of GM survey meter. On 15 March, ${ }^{132} \mathrm{Te} /{ }^{131} \mathrm{I}$ ratio was 0.20 for source term, 0.50 for air dust samplings of average data $(\mathrm{N}=5)$ in JAEA, and 0.36 by the estimation using conversion factor of GM survey meter.

Table 2. The temporal pattern of radionuclides' ratios in the air on 12 March and 15 March.

\begin{tabular}{|c|c|c|c|}
\hline On 12 March & ${ }^{132} \mathrm{Te} /{ }^{131} \mathrm{I}$ & ${ }^{133} \mathrm{I}^{131} \mathrm{I}$ & ${ }^{137} \mathrm{Cs} /{ }^{131} \mathrm{I}$ \\
\hline Source term by Katata et al at 12.00 & 1.50 & 1.10 & 0.10 \\
\hline $\begin{array}{l}\text { Air dust sampling average data }(\mathrm{N}=3) \text { at } 20 \\
\mathrm{~km}-\text { zone from Fukushima Prefecture at } \\
9: 00-13: 30\end{array}$ & 1.93 & & 0.06 \\
\hline $\begin{array}{l}\text { Estimated air concentration from measured } \\
\text { by clothing in FMU at } 12: 00^{*}\end{array}$ & 1.79 & 1.14 & 0.08 \\
\hline On 15 March & ${ }^{132} \mathrm{Te}^{131} \mathrm{I}$ & ${ }^{133} \mathrm{I}^{131} \mathrm{I}$ & ${ }^{137} \mathrm{Cs} /{ }^{131} \mathrm{I}$ \\
\hline Source term by Katata et al. at $20: 00$ & 0.20 & 0.10 & 0.01 \\
\hline $\begin{array}{l}\text { Air dust sampling average data }(\mathrm{N}-5) \text { at } \\
\text { JAEA (Tokai Village) at 3:00-21:00 }\end{array}$ & 0.50 & 0.12 & 0.08 \\
\hline $\begin{array}{l}\text { Air dust samplings in JAEA using our } \\
\text { conversion factor of GM survey meter at } \\
12: 00^{*}\end{array}$ & 0.36 & 0.11 & 0.06 \\
\hline
\end{tabular}

Radionuclide ratios were based on source term by Katata, et al. [7], air dust sampling data within $20 \mathrm{~km}$ radius the FDNPS by the local government of Fukushima Prefecture on 12 March [12], and air dust sampling by JAEA located in Tokai Village on 15-17 March [9]. * Estimated nuclides ratios by simulation were based on the nuclides compositions of clothing on 12 March or those of air dust samplings by JAEA on 15 March. 


\subsection{D-MC simulation of estimated thyroid equivalent dose at 1-year-old children by inhalation using body surface contamination}

We assumed that the distribution of contamination among evacuees/residents having measurement values in cpm would be representative of other evacuees/residents in the same district who had only categorical values, i.e., "No measurement value recorded", or "Specific Symbols". Using distributions in Figure 2, thyroid equivalent doses of 1-year-old children by inhalation were estimated by 2D-MC simulation in 12-14 March period (Table 3) and 15-17 March period (Table 4). Judging from A-D scores, the fitness of body surface contamination to group-specific log normal, exponential or Weibll distribution was practically satisfactory in Namie, Minamisoma, and the others groups. On the other hand, the distribution of Tomioka/Okuma/Futaba/Naraha group was heterogeneous and fitting to a log normal distribution was rather poor.

In 12-14 March period (Table 3), 50 percentile thyroid equivalent dose at 1-year-old children was highest in Minamisoma group (4.2 mSv), while 95 percentile dose was highest in Namie group $(86.0 \mathrm{mSv})$. In 15-17 March period (Table 4), 50 percentile thyroid equivalent dose was less than $1.6 \mathrm{mSv}$, and 95 percentile dose was less $16 \mathrm{mSv}$ in all groups.

If the same evacuee/resident exposed 3-times on 12, 15 and $16 \mathrm{March}$, his/her 50 percentile inhalation dose would be the sum of 50 percentile doses in Tables 3 and 4, for example, $4.3 \mathrm{mSv}$ for Namie group.

Table 3. Estimated thyroid equivalent dose of 1-year-old children by inhalation using 2D-MC simulation during 12-14 March period.

\begin{tabular}{cccc}
\hline 4 district-group & $\begin{array}{c}50 \% \text {-tile } \\
(90 \% \text { U.I. })\end{array}$ & $\begin{array}{c}90 \% \text {-tile } \\
(90 \% \text { U.I. })\end{array}$ & $\begin{array}{c}95 \% \text {-tile } \\
(90 \% \text { U.I. })\end{array}$ \\
\hline $\begin{array}{c}\text { Tomioka/Okuma/ } \\
\text { Futaba/Naraha }\end{array}$ & $0.1 \mathrm{mSv}$ & $0.6 \mathrm{mSv}$ & $1.0 \mathrm{mSv}$ \\
& $(0.1-0.3)$ & $(0.3-1.3)$ & $(0.5-2.0)$ \\
Namie & $2.7 \mathrm{mSv}$ & $40.8 \mathrm{mSv}$ & $86.0 \mathrm{mSv}$ \\
& $(1.4-5.5)$ & $(20.9-85.2)$ & $(80.1-91.9)$ \\
& & & \\
Minamisoma & $4.2 \mathrm{mSv}$ & $13.4 \mathrm{mSv}$ & $17.2 \mathrm{mSv}$ \\
& $(2.2-8.8)$ & $(6.9-28.0)$ & $(8.8-35.8)$ \\
& & & \\
The Others & $0.2 \mathrm{mSv}$ & $1.3 \mathrm{mSv}$ & $2.1 \mathrm{mSv}$ \\
& $(0.1-0.4)$ & $(0.7-2.6)$ & $(1.1-4.5)$ \\
\hline
\end{tabular}

The distributions (A-D scores) of body surface contamination in 4 district-groups were log normal (23.2), log normal (0.84), exponential (0.49), and $\log$ normal (2.21) for Tomioka/Okuma/Futaba/Naraha, Namie, Minamisoma, and the others, respectively. The U.I. is uncertainty interval.
Table 4. Estimated thyroid equivalent dose of 1-year-old children by inhalation using 2D-MC simulation during 15-17 March period.

\begin{tabular}{cccc}
\hline 4 district-group & $\begin{array}{c}50 \% \text {-tile } \\
(90 \% \text { U.I. })\end{array}$ & $\begin{array}{c}90 \% \text {-tile } \\
(90 \% \text { U.I. })\end{array}$ & $\begin{array}{c}95 \% \text {-tile } \\
(90 \% \mathrm{U} . \mathrm{I} .)\end{array}$ \\
\hline $\begin{array}{c}\text { Tomioka/Okuma/ } \\
\text { Futaba/Naraha }\end{array}$ & $0.2 \mathrm{mSv}$ & $5.4 \mathrm{mSv}$ & $13.2 \mathrm{mSv}$ \\
& $(0.1-0.3)$ & $(2.8-11.3)$ & $(6.8-27.6)$ \\
Namie & $0.8 \mathrm{mSv}$ & $8.2 \mathrm{mSv}$ & $15.7 \mathrm{mSv}$ \\
& $(0.4-1.7)$ & $(4.2-17.3)$ & $(8.1-32.9)$ \\
& & & \\
Minamisoma & $1.6 \mathrm{mSv}$ & $5.9 \mathrm{mSv}$ & $8.4 \mathrm{mSv}$ \\
& $(0.8-3.3)$ & $(3.0-12.3)$ & $(4.3-17.5)$ \\
& & & $12.7 \mathrm{mSv}$ \\
The Others & $1.2 \mathrm{mSv}$ & $8.3 \mathrm{mSv}$ & $(6.5-26.5)$ \\
\hline
\end{tabular}

The distributions (A-D scores) of body surface contamination in 4 district-groups were log normal (4.91), log normal (1.44), log normal (1.03), and Weibll (1.29) for Tomioka/Okuma/Futaba/Naraha, Namie, Minamisoma, and the others, respectively. The U.I. is uncertainty interval.

\section{Discussions}

In the present study, we proposed a new methodology for estimating thyroid equivalent dose by inhalation based on the levels of body surface contamination. Since the exposure levels would differ by the timing and route of evacuation, as well as by sheltering status at the time of radioactive plume, body surface contamination was a reasonable indicator of exposure, which reflected individual self-protective behavior.

Evacuation order was delivered to residents living in the $20 \mathrm{~km}$ zone from the FDNPS at evening on 12 March. About $93 \%$ of residents living in Tomioka, Okuma, Futaba and Naraha Towns evacuated to evacuation centers in Kawauchi Village, Tamura City, Kawamata Town, and Iwaki City as of midnight on 13 March [18]. Since these evacuation centers were not attacked by a plume released on $12 \mathrm{March}$, residents might expose to plume before or during evacuation. In contrast, many residents in Namie Town evacuated to an evacuation center on Tsushima area in Namie Town, which placed on borderline of $20 \mathrm{~km}$ zone from FDNPS. Although about $81 \%$ of residents in Namie Town evacuated as of midnight on 13 March [18], a plume on 12 March blew inland towards Namie Town and Minamisoma City. As to residents in Minamisoma City, evacuation order was delivered to only Odaka area, and about $30 \%$ of residents evacuated as of midnight on 13 March [18]. These differences in evacuation timing and route may be responsible for difference in body surface contamination levels and estimated thyroid doses among 4 districtgroups.

In the present study, we estimate thyroid equivalent dose of 1-year old children by inhalation based on body surface contamination levels. In order to convert GM survey meter measurement in cpm into radionuclides densities in $\mathrm{Bq} / \mathrm{cm}^{2}$, one has to know radionuclides' composition on body surface. Since we had 
simultaneously analyzed radionuclides' composition on clothing who evacuated on 12 March, and because the radionuclides' composition of air dust samplings at 20 $\mathrm{km}$-zone from FDNPS on the same day was published [12], we could accomplish the task. As to radionuclides' composition on body surface on 15-17 March, we assumed relative deposition velocity of ${ }^{132} \mathrm{Te}$ to ${ }^{131} \mathrm{I}$ would be same through 12 March to 17 March, and estimated nuclides composition on the body surface would be proportional to those composition in air at JAEA on 15 March. A total number of subjects having measurement values in cpm were 343 in Namie Town, 589 in Minamisoma City and these numbers were sufficient for illustrating the district-specific distribution of body surface contamination. On the other hand, these numbers were too small to illustrate a district-specific distribution in other area, and we had to pool subjects into Tomioka/Okuma/Futaba/Naraha group and the other group. By this reason, the distributions of body surface contamination in the latter district-groups were rather heterogeneous and uncertain in the present 2D-MC simulation. However, our estimates were very close to estimates based on thyroid measurements or whole body measurements.

In the UNSCEAR 2013 Fukushima Report, settlement-average thyroid doses during evacuation in 1year-old infants was estimated as follows: 0-46 mGy for Tomioka/Okuma/Futaba/Naraha Town, $37 \mathrm{mGy}$ and/or $59 \mathrm{mGy}$ for Namie Town, $6.4 \mathrm{mGy}$ or $45 \mathrm{mGy}$ for Minamisoma City, and 0-63 mGy for the other [4]. It was noted that UNSCEAR's estimates were a sum of inhalation and ingestion doses and based on an atmospheric transfer and dispersion model with Terada's source term [19]. It was said that the variability of thyroid inhalation dose could be from $30-50 \%$ of settlement-average thyroid doses up to about two to three times higher than settlement-average thyroid doses.

Tokonami et al. estimated thyroid doses of children based on direct thyroid measurements of 46 evacuees/residents, most of them from Namie Town. The median thyroid equivalent dose and the maximum dose for children were 4.2 and $23 \mathrm{mSv}$, respectively [3]. In the estimation, the authors hypothesized that subjects were exposed on 15 March. Recently, Kim et al. reported internal thyroid dose estimation at 1-year-old children mostly from inhalation during 15-23 March, 2011. The authors estimated thyroid dose by 1,080 direct thyroid measurements, about 3,000 radio-cesium measurements by WBC and the simulation of behavior pattern by atmospheric dispersion [2]. In order to estimate thyroid doses from WBC data, the authors assumed ${ }^{131} \mathrm{I} /{ }^{137} \mathrm{Cs}$ intake ratio being 3 , which was 2 - to 3 -times lower than those in the air. The 90 percentile of internal thyroid dose at 1-year-old children was $10-30 \mathrm{mSv}$ for Tomioka/Okuma/Futaba/Naraha Town, $20 \mathrm{mSv}$ for Namie Town, and $20 \mathrm{mSv}$ for Minamisoma City [2].

In the present report, inhalation thyroid doses were higher in Namie and Minamisoma groups than Tomioka/Okuma/Futaba/Naraha group during 12-14
March period as well as 15-17 March period. In addition, inhalation doses were higher during 12-14 March period than those during 15-17 March period. This was a new finding that a plume on 12 March had suffered people living Namie Town and Minamisoma City than expected before. Our 50 and 90 percentiles of thyroid equivalent dose at 1-year-old children in Namie group were 2.7 $\mathrm{mSv}$ and $40.8 \mathrm{mSv}$ during 12-14 March periods, respectively, and were within a 2-times difference range of Tokonami's estimates. Our 90 percentile estimate was also higher than those by Kim, i.e. $20 \mathrm{mSv}$. While, our estimates for Tomioka/Okuma/Futaba/Naraha group were lower than Kim's estimates: $0.6 \mathrm{mSv}$ during 12-14 March periods and 5.4 mSv during 15-17 March periods vs. 10-30 mSv. Since radio-cesium detected by WBC could be derived from acute inhalation during early phase of the accident but also from chronic ingestion, radio-iodine uptake scenario could influence the estimation.

We proposed in the present study a new methodology for estimating thyroid equivalent dose using districtspecific body surface contamination in cpm. However, it is still in a developmental stage and has several sources of uncertainty. First, the natural removal rate (half-life time) was chosen as 15 hours based on one report [10]. However, it is not certain whether radioactive particles or elemental iodine behave like submicron silica particles. In addition, natural removal rate may be influenced meteorological condition, human activity and physicochemical property of skin, hair and clothing. Second, we assumed deposition velocity following a uniform distribution ranging from 0.1 to $0.5 \mathrm{~cm} / \mathrm{s}$. The deposition velocity in experimental conditions was reported to be quite heterogeneous and changed along with the physicochemical property of surface and meteorological condition $[15,16]$. In the present study, we adopted values reported in the FDNPS accident, the Windscale accident, and the SL-1 accident $[13,14,16]$. However, it is not certain whether these values can be applied to human skin, hair or clothing. Third, the chemical form of radio-iodine was uncertain. In the present study, we adopted $20 \%$ elementary iodide, $30 \%$ methyl-iodine and $50 \%$ particulate form as Katata reported [7]. If the fraction of methyl iodine increases with time, the deposition velocity of radio-iodine will decrease, and then, our estimation will tend to underestimate. Fourth, we chose the constant respiration rate $\left(0.35 \mathrm{~m}^{3} / \mathrm{h}\right)$ at 1-year-old children of lightly exercise during evacuation, and a thyroid uptake rate of $30 \%$. These parameters are reported in ICRP Publication 68 [20]. Since the variation of thyroid uptake rate is known in Japanese, a thyroid uptake rate may become one of uncertainty in our report.

As to our obtained data from the Fukushima government office, there were only rounded address and age, date of screening, screening place, and measurements data in cpm or "Specific symbols". It was not possible to correlate our data with the resident personal behavior record of the Fukushima Health Management Survey [21] or measurement data such as 
WBC measurement [22]. Furthermore, we could not classify an affiliation of a person who was screened body surface contamination survey. If first responders or TEPCO workers of the early phase in the FDNPS accident were contented in our data list, their contamination level might be quite different from those of residents [23]. We are planning to correlate GM survey meter data to WBC measurements and resident personal behavior record in order to clarify these issues. There were categorical data in our data set, such as "No measurement value recorded", and "Specific symbols". In order to clarify their meaning, we began conducting questionnaire survey to surveyors who conducted screening survey for body surface contamination during the first 6 days of the FDNPS accident. It is still premature to conclude, but several surveyors answered "Specific symbols" represented a condition where body surface contamination was over BG but less than predetermined screening level, i.e., 13,000 cpm.

\section{Conclusion}

Thyroid equivalent dose of 1-year-old children by inhalation was estimated by 2D-MC simulation using four district-specific distributions of body surface contamination in cpm. Inhalation dose was higher in Namie and Minamisoma groups than other districts due to exposure to a plume on 12 March, 2011. Our estimates were lower than UNSCEAR's estimates, partly because ingestion dose was not included.

\section{Acknowledgment}

This study was supported by the funding from the Ministry of Environment, Japan.

\section{References}

1. S. Midorikawa, S. Suzuki, and A. Ohtsuru, Science 352 (6286), 666 (2016)

2. E. Kim, O. Kurihara, N. Kunishima, T. Momose, T. Ishikawa, and M. Akashi, J. Radiat. Res. 57 Suppl 1, i1 18 (2016)

3. S. Tokonami, M. Hosoda, S. Akiba, A. Sorimachi, I. Kashiwakura, and M. Balonov, Sci. Rep. 2, 507 (2012)

4. United Nations Scientific Committee on the Effects of Atomic Radiation, UNSCEAR 2013 Report Annex A: Levels and effects of radiation exposure due to the nuclear accident after 2011 great eastJapan earthquake and tsunami (United Nations, New York, 2014)

5. H. Kondo, J. Shimada, C. Tase, T. Tominaga, H. Tatsuzaki, M. Akashi, K. Tanigawa, Y. Iwasaki, T. Ono, M. Ichihara, Y. Kohayakawa, and Y. Koido, Health Phys. 105 (1), 11 (2013)
6. T. Ohba, M. Miyazaki, H. Sato, A. Hasegawa, M. Sakuma, T. Yusa, F. Shishido, and A. Ohtsuru, Health Phys. 107 (1), 10 (2014)

7. G. Katata, M. Chino, T. Kobayashi, H. Terada, M. Ota, H. Nagai, M. Kajino, R. Draxler, M. C. Hort, A. Malo, T. Torii, and Y. Sanada, Atmos. Chem. Phys. Discuss. 15 (2), 1029 (2015)

8. H. Ogino, T. Ichiji, and T. Hattori, Radiat. Prot. Dosimetry 151 (1), 36 (2012)

9. S. Furuta, S. Sumiya, H. Watanabe, M. Nakano, K. Imaizumi, M. Takeyasu, A. Nakada, H. Fujita, T. Mizutani, M. Morisawa, Y. Kokubun, T. Kono, M. Nagaoka, H. Yokoyama, T. Hokama, T. Isozaki, M. Nemoto, Y. Hiyama, T. Onuma, C. Kato, and, T. Kurachi, Results of the Environmental Radiation Monitoring Following the Accident at the Fukushima Daiichi Nuclear Power Plant-Interim Report (Ambient Radiation Dose Rate, Radioactivity Concentration in the Air and Radioactivity Concentration in the Fallout) (JAEAReview, Tokai, 2011)

10. H. Hession, M. Byrne, S. Cleary, K. G. Andersson, and J. Roed, J. Environ. Radioact. 85 (2-3), 196 (2006)

11. International Commission on Radiological Protection, Age-dependent Doses to Members of the Public from Intake of Radionuclides - Part 4 Inhalation Dose Coefficients (ICRP Publication 71, Oxford, 1995)

12. The local government of Fukushima Prefecture, The result of gamma-ray radionuclide analysis about air dust sampling in emergency monitoring (Japanese) [online]. Available at: http://www.pref.fukushima.lg.jp/uploaded/attachme nt/166539.pdf. Accessed 10 August 2016.

13. H. Amano, M. Akiyama, B. Chunlei, T. Kawamura, T. Kishimoto, T. Kuroda, T. Muroi, T. Odaira, Y. Ohta, K. Takeda, Y. Watanabe, and T. Morimoto, J. Environ. Radioact. 111, 42 (2012)

14. A. C. Chamberlain, Q. J. R. Meteorol. Soc. 85 (366), 362 (1959)

15. G. A. Sehmel, Atmos. Environ. 14 (9), 983 (1980)

16. F. A. Gifford Jr. and D. H. Pack, Surface deposition of airborne material, Technical Progress Review, Nuclear Safety 3 (4), 205 (1963)

17. N. G. Stewert and R. N. Crooks, Nature 182 (4636), 627 (1958)

18. The National Diet of Japan, The official report of The Fukushima Nuclear Accident Independent Investigation Commission (The National Diet of Japan-The Fukushima Nuclear Accident Independent Investigation Commission, Tokyo, 2012) 
19. H. Terada, G. Katata, M. Chino, and H. Nagai, J. Environ. Radioact. 112C, 141 (2012)

20. International Commission on Radiological Protection, Dose Coefficients for Intakes of Radionuclides by Workers (ICRP Publication 68, Oxford, 1994)

21. S. Yasumura, M. Hosoya, S. Yamashita, K. Kamiya, M. Abe, M. Akashi, K. Kodama, and K. Ozasa, Journal of Epidemiology 22 (5), 375 (2012)

22. K. Kamiya, T. Ishikawa, S. Yasumura, A. Sakai, T. Ohira, H. Takahashi, A. Ohtsuru, S. Suzuki, M. Hosoya, M. Maeda, H. Yabe, K. Fujimori, S. Yamashita, H. Ohto, and M. Abe, Radiat. Prot. Dosimetry, in press (2016)

23. T. Nakano, E. Kim, K. Akahane, T. Tominaga, H. Tatsuzaki, O. Kurihara, and N. Sugiura, Direct measurement for highly-exposed TEPCO workers and NIRS first responders involved in the Fukushima NPS accident, The 1st NIRS symposium on reconstruction of early internal dose in the TEPCO Fukushima Daiichi nuclear power station accident (National Institute of Radiological Sciences, Chiba, 2012) 